\title{
EDUCAÇÃO DO CAMPO E TURISMO RURAL COMO RESISTÊNCIAS À EXPANSÃO DESENFREADA DO AGRONEGÓCIO: CURSOS PROPOSTOS E VIABILIZADOS DE DESENVOLVIMENTO AGROECOLÓGICO ENQUANTRO ESTRATÉGIAS DE GESTÃO SOCIOAMBIENTAL
}

\author{
FIELD EDUCATION AND RURAL TOURISM AS \\ RESISTANCES TO THE UNCONFERRED EXPANSION OF \\ AGROBUSINESS: COURSES PROPOSED AND MADE \\ FEASIBLE FOR AGROECOLOGICAL DEVELOPMENT AS \\ STRATEGIES FOR SOCIO-ENVERIONMENTAL \\ MANAGEMENT
}

Vagner Luciano de Andrade ${ }^{1}$ Ana Paula da Silva Dib ${ }^{2}$

\section{RESUMO}

Em tempos latentes de etnocentrismo e de múltiplas mazelas urbanoindustriais, o desenvolvimento camponês e a paisagem cultural rural se veem ameaçados e destituídos de suas múltiplas essências e legitimidades. Movimentos sociais de diferentes partes do país a partir de uma historicidade de resistência e reanálise da realidade agrícola brasileira apresentam a cultura camponesa observada particularmente com seus contextos, signos, significados e significantes. Nesta multiplicidade de ação, a ecologia campesina e a gestão ambiental se protagonizam como frentes de resistência à expansão desenfreada do agronegócio capitalista, neoliberal e insustentável. Neste sentido, o presente trabalho, a partir de ampla revisão bibliográfica destaca as propostas atuais e/ou pretéritas de viabilização de cursos interdisciplinares, técnicoprofissionalizantes e/ou graduação-especialização nas áreas de Agroecologia, Educação do Campo e Turismo Rural enquanto frentes estratégicas de resistência, ressignificação e consecutivo desenvolvimento sustentável dos estudantes camponeses.

Palavras-chave: Agroecologia, Ecologia Campesina, Educação do Campo, Gestão Ambiental, Turismo Rural.

\section{ABSTRACT}

In latent times of ethnocentrism and multiple urban-industrial ills, peasant development and the rural cultural landscape are threatened and deprived of their multiple essences and legitimacy. Social movements from different parts of the country based on a history of resistance and reanalysis of the Brazilian agricultural reality present the peasant culture observed particularly with its

\footnotetext{
1 Graduado em Ciências Biológicas (FIAR/2018), Geografia e Análise Ambiental (UNIBH?2007), Gestão Ambiental (UNICESUMAR/2019) e História (UNICESUMAR/2018). Discente dos Cursos de Agroecologia e Agronegócio (UNITAU). Voluntário da Rede Ação Ambiental. E-mail: reacao@yahoo.com. Lattes: http://lattes.cnpq.br/3803389467894439. ORCID 0000-0003-4679-7177.

2 Graduada em Agronomia pela Universidade de Taubaté (1994), mestrado em Agronomia (Horticultura) pela Universidade Estadual Paulista Júlio de Mesquita Filho (2000) e doutorado em Zootecnia pela Universidade Estadual Paulista Júlio de Mesquita Filho (2009). Docente dos Cursos de Agroecologia e Agronegócio (UNITAU). E-mail: anadib@ead.unitau.com.br. Lattes: http://lattes.cnpq.br/5172409410425051, ORCID.
}

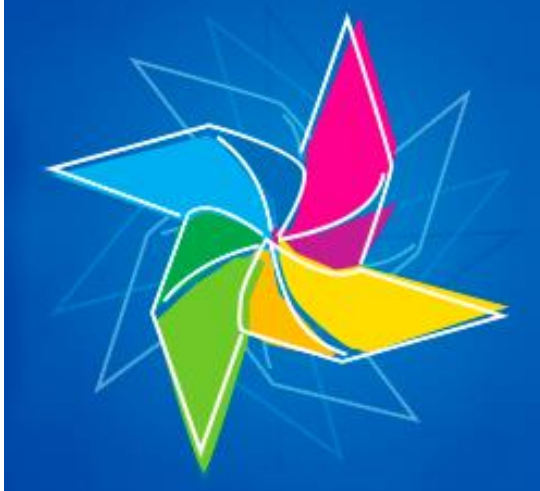


contexts, signs, meanings and signifiers. In this multiplicity of actions, peasant ecology and environmental management play a leading role in resisting the unbridled expansion of capitalist, neoliberal and unsustainable agribusiness. In this sense, the present work, based on a wide bibliographic review, highlights the current and / or past proposals for making interdisciplinary, technical-professional and / or undergraduate-specialized courses feasible in the areas of Agroecology, Rural Education and Rural Tourism as strategic fronts resistance, resignification and consecutive sustainable development of peasant students.

Key words: Agroecology, Peasant Ecology, Rural Education, Environmental Management, Rural Tourism.

\section{INTRODUÇÃO}

Literalmente, o desenvolvimento agrícola do Brasil foi uma história capitalista contextualizada por latifúndios e latifundiários, segundo a obra "Quatro séculos de latifúndio" de autoria de Alberto Passos Guimarães. É excepcionalmente imprescindível, no corpo social presente, que novas observações se concretizem sobre as existências camponesas desiguais, objetivando colaborar com novos ângulos e reflexões sobre a composição do espaço agrário (FIGURA 01), marcando a emergência de instituição e de uma organização agrária potencialmente local. Essa urgência de novos fundamentos teóricos, por sua vez, se destacam como intensamente cruciais à concepção dos aspectos societários relativos à constituição do desenvolvimento sustentável rural. Neste momento, novos estudos projetados nesta temática essencial se constituem enquanto de suma importância oferecendo novos subsídios ao debate presente na comunidade acerca de agricultura familiar, do desenvolvimento rural, das dinâmicas rurais brasileiras, da estrutura fundiária e conflitos agrários, do êxodo rural e reforma agrária, dos fatores de expulsão do campo, dos impactos agrícolas, da ruralidade brasileira e sistemas agropecuários.

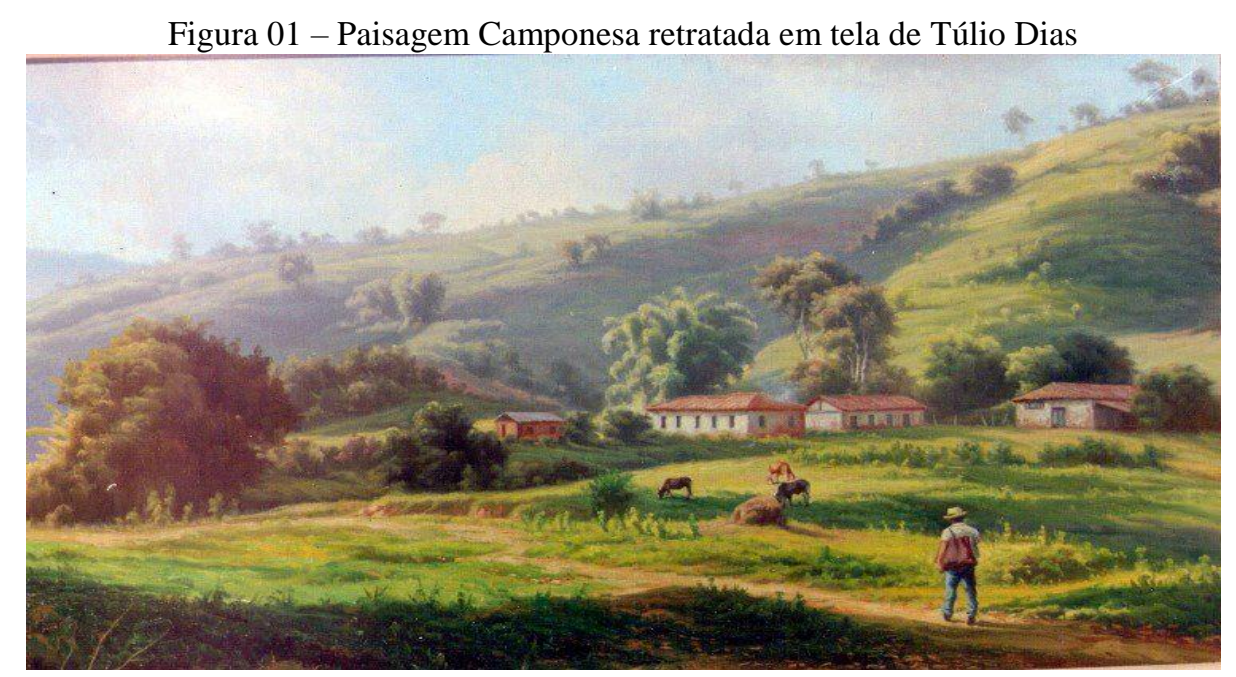

Fonte: https://www.catalogodasartes.com.br/obra/AczzGz/. Acessado em: 22/11/2020.

Pensar no camponês, implica pensar outras realidades alternativas, em especial, indígenas e negros, para reescrita da história e para se extirpar erros pretéritos. O vexame da 
exploração de mão de obra de origem africana, sob o modelo desumano e ilegal da escravidão é certamente um dos maiores vergonhas históricas do povo brasileiro com sequelas até hoje percebidas no âmago da sociedade através da exclusão, do preconceito a que foram submetidos os afrodescendentes e os afro-brasileiros. Para Marquese (2006, p.11):

\begin{abstract}
Nos séculos que se seguiram ao colapso do Império romano, a escravidão não desapareceu por completo na Europa ocidental e mediterrânea. No entanto, no decorrer da Baixa Idade Média, a escravidão como sistema de trabalho deixou de existir no Ocidente europeu, excetuando-se os países do Mediterrâneo, isto é, das penínsulas Ibérica e Itálica. Mesmo aí, ela foi, nos séculos XIV e XV, tão-somente uma instituição urbana, com importância limitada no conjunto da economia; o emprego em larga escala de cativos na produção agrícola havia se tornado residual nestas últimas regiões. A recriação do escravismo, com o emprego massivo de escravos nas tarefas agrícolas, seria realizada por portugueses e espanhóis só após a segunda metade do século $\mathrm{XV}$, com a introdução da produção açucareira nas ilhas atlânticas orientais (Canárias, Madeira, São Tomé), e, no século XVI, com a colonização da América.
\end{abstract}

O país foi o último a abolir a escravidão, mas muitos latifundiários e comerciantes se enriqueceram através do sangue e do suor do povo negro, que além de desterrado de sua terra natal, era açoitado, violentado, humilhado publicamente. As senzalas retratavam as condições de extrema aspereza e perversidade que o branco utilizava para mantê-los em cativeiro. Leonídio (2017, p.14) atesta que:

um dos traços mais marcantes do processo de socialização que se dava nos domínios da casa grande e da senzala é o sadismo: sadismo de conquistador contra conquistado, de senhor contra escravo, de homem contra mulher, mas também de filhos de senhores contra filhos de escravos, apelidados estes sintomaticamente de leva-pancadas. E assim divertia-se, mas também aprendia o sinhozinho as normas de convívio social entre quem manda e quem obedece no Brasil

Mal alimentados, dormindo no chão puro, ou trabalhando mais de 14 horas, a idade máxima de expectativa de vida era de 35 anos. O resultado é que na atualidade os negros ainda são vítimas da sociedade vigente sendo necessário e permanente políticas públicas e aparatos legais que legitimem sua dignidade, enquanto ser humano. Segundo Leonídio (2017, p.15):

E assim, no exercício da maldade nossa de cada dia, perpetuamos o legado de desigualdades históricas, fruto do ventre podre da escravidão. Repetimos, um tanto inconscientemente, o gesto original que torna inadmissível a dignidade e o direito dos pobres, feitos para machucar e para doer. E como não são humanos como nós, ninguém faz caso de seu sofrimento.

No escopo da paisagem, a diferenciação entre donos e seus subalternos se materializa. Assim é emergencial a avaliação dos sistemas de concepção e desenvolvimento socioeconômico da paisagem, pelo meio de da contextualização dos embates e contradições entre atividades urbanas e rurais. Entender a estrutura fundiária inspira na sociedade 
capitalista e consumista, a iminente ideia da escassez para que se utilize moldes de desenvolvimento sustentável que motivem ao homem se harmonizar com os recursos naturais essenciais a evolução e a qualidade de vida, sem, contudo, gerar consequências socioambientais inconversíveis ao meio ambiente. Acerca desta veracidade socioeconômica, mas, principalmente ambiental e igualmente cultural, Antunes-Rocha, Freitas \& Pinho (2013, p. 20) observam dados relevantes e enfatizam que:

há no Brasil dois modelos que a literatura vem denominando de Agronegócio e/ou Agricultura Industrial e de Agricultura Familiar ou Agricultura Camponesa. A cada modelo, vincula-se uma forma de posse e de uso e, consequentemente, de concepção de campo e de sociedade. A partir do entendimento do agronegócio e do campesinato como opostos, enfatizamos a presença no Brasil de dois territórios distintos: o território da agricultura familiar camponesa e o território da latifúndio e do agronegócio.

Essa classificação agrária, econômica e política se prorroga com o estabelecimento do capitalismo pós-moderno e suas proposições urbano-industriais com ascensão dilaceradora do agronegócio e a expansão da ação de latifundiários, ao passo que essa classe social se enraizou incluindo representações políticas nas dimensões estadual, federal e municipal. Conforme Ribeiro, Galizoni \& Silvestre (2004), com a colonização portuguesa, a terra e seus recursos naturais foram partilhados entre famílias de empresariais ou nobres, originando o recente paradigma histórico brasileiro de administração rural majoritariamente enraizado. Sobre a historicidade do conflito entre estes sujeitos diferentes, Antunes-Rocha, Freitas \& Pinho (2013, p. 20) afirmam que:

O território do latifúndio e do agronegócio compreende as grandes propriedades, grilos, grilheiros, exploração do trabalho, grandes empresas capitalistas, crimes ambientais, mecanização intensa, superprodução, improdutividade, especulação imobiliária, violência contra a pessoa e concentração do poder econômico e político. De forma oposta, o território da agricultura familiar camponesa, relativo aos camponeses com ou sem terra, compreende a luta pela terra, pequenas propriedades, pequenas posses, cooperativismo, produção familiar, menos impacto ambiental,ocupações de terras e assentamentos rurais,. Esses dois territórios são ideologicamente opostos e materializados através da posse e propriedade da terra, da produção agropecuária e de suas ações políticas.

Segundo Ribeiro, Galizoni \& Silvestre (2004), essa figura contraditória dos latifúndios e latifundiários “foi - em algumas regiões ainda é - tão poderosa que marcou a história e a importância de todas as demais formas de organização produtiva rural”, seguida de discriminação e expulsão. No contraponto deste modelo de apropriação fundiária, a literatura considera que, no Brasil perduram agricultores autônomos que usam em caráter comunitário, a propriedade em sistema de empreendimento familiar, desde épocas coloniais. São as 
chamadas populações tradicionais ${ }^{1}$ com concepções existenciais, culturais, filosóficas, políticas, psicológicas e sociológicas coexistentes e alternativos (QUADRO I). Habitaram cargos subordinados nessa fase, pois não se destacavam na geração de mercadorias de exportação e nem muito menos eram donos de bens ou escravos (RIBEIRO, GALIZONI \& SILVESTRE, 2004).

Quadro I - Contextualização do histórico antagonismo no mundo rural brasileiro

\begin{tabular}{|l|l|}
\hline \multicolumn{1}{|c|}{ Território do latifúndio e do agronegócio } & \multicolumn{1}{c|}{ Território da agricultura familiar camponesa } \\
\hline Grandes propriedades & Pequenas propriedades \\
\hline Grandes empresas capitalistas & Pequenas posses \\
\hline Grilos e grilheiros & Assentamentos rurais \\
\hline Exploração do trabalho & Cooperativismo \\
\hline Crimes ambientais & Menos impacto ambiental \\
\hline Mecanização intensa & Agroecologia \\
\hline Superprodução & Produção familiar \\
\hline Improdutividade & Ocupaçoses de terras \\
\hline Especulação imobiliária & Luta pela terra \\
\hline Violência contra a pessoa & Relações familiares \\
\hline Concentração do poder econômico e político & Camponeses com ou sem terra \\
\hline
\end{tabular}

Adaptado de Antunes-Rocha, Freitas \& Pinho (2013, p. 20)

As primícias escravistas e senhoriais da aristocracia brasileira sempre desclassificaram socialmente as cidadãos que viviam do seu próprio emprego. O dado mais intricado de todos, obviamente foi o apartamento cultural das populações tradicionais camponesas (RIBEIRO, GALIZONI \& SILVESTRE, 2004). As administrações públicas esporadicamente os abrangeram, perfazendo com que eles adentrassem continuamente em status de marginalidade nos grandes mercados. Isso incentivou e consolidou as disputas que se articularam em várias localidades brasileiras. Por isso, seus modelos de organização, representação, cultura, usos e saberes locais foram desconsiderados.

Nascimento (2009) cita Lisita $\left(1992^{2}\right)$ afirmando que "quando há resistência dos camponeses/as, estes enfrentam a ira e a violência das velhas oligarquias rurais que mantêm o monopólio dos latifúndios improdutivos". Sobre os conflitos, estudos de Antunes-Rocha, Freitas \& Pinho (2013, p. 20-21) citam fundamentações, a partir de escritos de Girardi $\left(2013^{3}\right)$ :

\footnotetext{
${ }^{1}$ Artigo $1^{\mathrm{o}}$, parágrafo $1^{\mathrm{o}}$, Inciso I do Decreto Federal no 7.352 de 04 de novembro 2010; populações do campo: os agricultores familiares, os extrativistas, os pescadores artesanais, os ribeirinhos, os assentados e acampados da reforma agrária, os trabalhadores assalariados rurais, os quilombolas, os caiçaras, os povos da floresta, os caboclos e outros que produzam suas condições materiais de existência a partir do trabalho no meio rural;

${ }^{2}$ LISITA, C. Sistema de produção e especulação agrícola: o caso do cerrado. In: Anais do Encontro Nacional de Geografia Agrária, 11, 1992, Maringá/PR.

${ }^{3}$ GIRARDI, E. P. Proposição teórico-metodológica de uma cartografia geográfica crítica e sua aplicação no desenvolvimento do atlas da questão agrária brasileira. 2008. 347 f. Tese (Doutorado em Geografia) Faculdade de Ciências e Tecnologia, Universidade Estadual Paulista, Presidente Prudente, 2008. Disponível em <https://repositorio.unesp.br/handle/11449/105064> Acesso em: 20 maio 2020.
} 
Essas formas de ocupar e de usar a terra não ocorrem sem conflitos. Daí a imensa luta que ocorre no Brasil desde o período colonial. Lutas ocorridas em tempos e espaços diferenciados e protagonizadas por sujeitos motivados pela situação de expropriação e violência. (...). Esta violência ocorre paralelamente à agricultura altamente produtiva que caracteriza o agronegócio. A Comissão Pastoral da Terra documenta desde a década de 1980 as ocorrências de conflitos e violências no campo brasileiro, cujos dados são publicados desde 1984 no "Caderno Conflitos no Campo". (...). O leste do Pará e o norte do Maranhão configuram uma região de concentração da violência. Esta região é caracterizada pela grande população assentada e, por fazer parte de fronteira agropecuária, com predomínio do latifúndio. Desta forma, o enfrentamento é mais evidente, sendo os camponeses e trabalhadores rurais submetidos a toda sorte de violência e exploração por parte de fazendeiros, grandes posseiros e grileiros.

Documentadamente em todas as etapas da coletividade humana perseveraram embates entre posições dominantes e seus subordinados excetuando-os dos recursos decisórios. Moura (2014, p. 52) informa como fator determinante, a aristocracia escravocrata da Antiguidade, a discordância entre os habitantes livres e os cativos na Idade Média, o antagonismo entre o nobre feudal e os vassalos e de novo, inoportunamente entre ricos e plebeus; com a Revolução Industrial, a partir do século XIX, a disputa entre capitalistas e assalariados. De acordo com Ribeiro, Galizoni \& Silvestre (2004), a evolução técnica na agricultura intensificou ainda mais essa exclusão no cerne da sociedade. A ampliação da agropecuária, a partir das decênios de 1960/1970, instigada por empréstimo rural e capital público, realçou a posição privada e a natureza patronal do meio agrário brasileiro. Nascimento (2009, p. 17) declara que:

A agricultura familiar camponesa foi abandonada, ao longo do século XX, pelas políticas públicas do Estado. A política agrícola do Estado prioriza a agricultura capitalista patronal, baseado na monocultura exportadora que busca atender ao mercado global, marginalizando por outro lado, a agricultura familiar camponesa destinada à subsistência e ao mercado local.

Isso persuadiu as migrações, à proporção que o camponês comum se viu rodeado pelos latifúndios, sem benefícios e encantado pela enganosa esperança de qualidade de vida das urbes (RIBEIRO, GALIZONI \& SILVESTRE, 2004). Acerca de aumento na concentração de terra, na nação (Quadro II), Antunes-Rocha, Freitas \& Pinho (2013, p. 20) afirmam que:

os estabelecimentos rurais de menos de 10 ha. ocupam menos de $2,7 \%$ da área total ocupada por estabelecimentos rurais nos três últimos Censos Agropecuários - 1985. 1996 e 2006 - enquanto que a área ocupada pelos estabelecimentos de mais de 1000 ha. concentram mais de 43,0\% da área total nestes anos. Em termos de números de estabelecimentos, contudo, a proporção se altera radicalmente, uma vez que os estabelecimentos de menos de 10 ha. passam a concentrar um percentual acima de 47,0\%, enquanto os estabelecimentos de maios de 1000 ha. Concentram, respectivamente, $0,87 \%, 1,02 \%$ e $0,91 \%$ do número total de estabelecimentos (IBGE, 2009). Esses dados denunciam a manutenção da desigualdade na distribuição da terra no País, visto que, se analisarmos os números das décadas passadas observam-se poucas alterações. 
Quadro II - área dos estabelecimentos rurais segundo estrato de áre no Brasil -1985/2006

\begin{tabular}{|l|c|c|c|}
\hline \multirow{2}{*}{ Estrato da Área } & \multicolumn{2}{|c|}{ Área dos estabelecimentos rurais por hectare } \\
\cline { 2 - 4 } & $\mathbf{1 9 8 5}$ & $\mathbf{1 9 9 6}$ & $\mathbf{2 0 0 6}$ \\
\hline Menos de 10 hectares & 9.986 .637 & 7.882 .194 & 7.798 .607 \\
\hline De 10 a menos de 100 & 69.565 .161 & 62.693 .585 & 62.893 .091 \\
\hline De 100 a menos de 1000 & 131.432 .667 & 123.541 .517 & 112.696 .478 \\
\hline De 1000 a mais & 163.940 .667 & 159.493 .949 & 146.553 .218 \\
\hline TOTAL & 374.924 .421 & 353.611 .246 & 329.941 .393 \\
\hline
\end{tabular}

Fonte: IBGE, 2009 apud Antunes-Rocha, Freitas \& Pinho, 2013, p. 19 (adaptado)

Sobreviver neste cenário de incerteza é demasiadamente complexo. Ribeiro, Galizoni \& Silvestre (2004) argumentam sobre a área mineira do Alto Jequitinhonha, onde os lavradores exercem o gerenciamento sustentável dos recursos naturais que são usufruídos em conjunto. Apesar de serem parcialmente reduzidos territorialmente, eles lançaram uma regulamentação cooperativa efetivada pelos próprios grupos que determinam o consumo, a poupança e a gestão dos estoques de bens e recursos. A coletividade é o multiforme organizacional cultural que opera na articulação dos cultivadores, estruturando as particularidades familiares, ambientais e históricas (RIBEIRO, GALIZONI \& SILVESTRE, 2004).

De outro lado, a família é o centro de projeto de produção e de reprodução física e cultural. Núcleo familiar e comunidade outorgam uma perspectiva da diversidade dos ângulos econômicos, sociais e culturalmente pertinentes do Jequitinhonha. Sobre a relevância da agricultura familiar no país, Antunes-Rocha, Freitas \& Pinho, (2013, p. 20) citam dados do IBGE, do ano de 2009:

Esta forma de posse tem impacto no uso. Enquanto as grandes propriedades dedicam-se à produição para exportação, as médias e pequenas são responsáveis por cerca de $70 \%$ da produção de alimentos consumidos no país ( $87 \%$ da mandioca, $70 \%$ do feijão, $46 \%$ do milho, $38 \%$ do café, $34 \%$ do arroz, $58 \%$ do leite, $59 \%$ dos suínos, $50 \%$ das aves, e $30 \%$ dos bovinos, entre outros produtos). No entanto recebe apenas $25 \%$ do financiamento destinado à agricultura e emprega $77 \%$ do pessoal ocupado no trabalho agrícola

Esta veracidade da agricultura familiar revalida os argumentos supracitados de metamorfose agroindustrial exportador ao qual, propriedades do país inteiro foram sido submetidas nas últimas décadas do século XX. Assim, a matriz de desenvolvimento agrário camponês deve ser a força matriz na posse de terras e recursos naturais. Recordando o modelo do Alto Jequitinhonha, estas comunidades estão conjuntas ao meio que utilizam para conquistar e formular uma intricada ${ }^{4}$ base estrutural sobre o uso dos recursos e sua

\footnotetext{
${ }^{4}$ Cultura camponesa: palavra de origem latina, colere, que significa "cultivar, criar, tomar conta, cuidar" (Chauí, 1997, p. 292) e expressa ação marcada pelo cuidado. Tomada abstratamente, para alcançarmos seu significado geral, cultura é toda criação humana resultante das relações entre os seres humanos e deles com a natureza que leva ao estabelecimento de modos de vida. Trata-se da criação e da recriação que emergem daquelas relações em
} 
manutenção popular (RIBEIRO, GALIZONI \& SILVESTRE, 2004). Mas essa suposta

liberalidade no emprego dos recursos renováveis se limita aos integrantes da grupo. Este é um dado fundamental a ser considerado na constituição das regras de utilização dos recursos. Há uma grandeza de benesses que o ambiente propicia para o uso das famílias. Como estes recursos são disponibilizados pela natureza, pode-se cogitar que não apresentem funções regulamentadas pela comunidade, sendo então utilizados a vontade das grupos, desregradamente e sem qualquer aspecto de restrição (RIBEIRO, GALIZONI \& SILVESTRE, 2004). Pelo contrário, indubitavelmente é um sistema de sustentabilidade a ser disseminado e empregado contrapondo-se a matriz insustentável da agricultura capitalista:

\begin{abstract}
A atividade agropecuária desenvolvida nas grandes propriedades é responsável pelo uso indiscriminado de agrotóxicos (a monocultura produz desequilíbrios na natureza e consequentemente surgem as pragas), esgotamento e contaminação dos recursos hídricos e dos solos, diminuição da mão-de-obra pelo uso intensivo da mecanização, concentração de riquezas e aumento da pobreza nas periferias urbanas do país (GIRARDI, 2013 apud ANTUNES-ROCHA, FREITAS \& PINHO, 2013, p. 20).
\end{abstract}

Não obstante o que se nota com o latifúndio é muito, sendo que Ribeiro, Galizoni \& Silvestre (2004), proclamam que nas comunidades rurícolas, as diretrizes de extração desses recursos assumem moldes de administração comunitária das ofertas da natureza. Os lugares de retirada são regidos por normas que fixam a precisão das famílias e comunidades com os bens em debate. Graças à ordenação, manutenção e percepção, essas famílias adquirem o status de subsistir com inexistência de chuva, migrações temporárias ou definitivas, sazonalidade do emprego agrícola e falta ocasional de alguns recursos. De acordo com o trabalho dos escritores, presumir e experimentar sua localidade ${ }^{5}$ é ao mesmo momento status para normatizá-lo, ao passo que recurso fundamental para gerar medidas produtivas sutis e constatar novos tipos de recursos. A sabedoria comunitária é a outra característica do pertencer, do produzir e do gerir adequado àquele diminuto território (RIBEIRO, GALIZONI \& SILVESTRE, 2004) que se soma às ângulos do saber escolar, acaso este se atribuía das alegações da pedagogia camponesa. Para Cruz (2012, p. 598):

\footnotetext{
que os humanos, ao transformarem o mundo, simultaneamente transformam a si próprios. Essas transformações se dão na ordem material, quando a criação e a recriação como ato humano tomam materiais da natureza, dando a eles formas que não possuíam até então (TARDIN, 2012, p. 180-188).

${ }^{5}$ Territorialidade camponesa: Em se tratando do campesinato, ele se constitui a partir de uma diversidade de sujeitos sociais históricos que se forjaram culturalmente numa íntima relação familiar, comunitária e com a natureza, demarcando territorialidades com as transformações necessárias à sua reprodução material e espiritual, gerando uma miríade de expressões particulares que, ao mesmo tempo, respaldam-se em elementos societários gerais, marcando sua humanização e humanizando a natureza, em um intricado complexo de agroecossistemas. Nesses termos, o campesinato confirma e exige tomar o tratamento da cultura em sua pluralidade; trata-se, portanto, de culturas do modo de ser de cada sociedade, nas quais se supera a pretensão de que haja "a cultura" e, fora dela, a "não cultura", como, na particularidade no campo, tem-se as culturas camponesas (TARDIN, 2012,
} p. 181). 
A relação com o território e a territorialidade: outra característica marcante desses grupos é uma forte relação com o território e com o sentido de territorialidade. Essas comunidades normalmente têm longa história de ocupação territorial sobre os espaços em que vivem, sendo comum várias gerações ocuparem a mesma área. Essa história de ocupação se expressa numa relação de ancestralidade, memória e sentido de pertencimento em relação a certas áreas e lugares específicos. O território tem, para esses grupos, importância material (base de reprodução e fonte de recursos) e forte valor simbólico e afetivo (referência para a construção dos modos de vida e das identidades dessas comunidades). A constituição dos territórios é caracterizada por grande diversidade de modalidades de apropriação da terra e dos recursos naturais (apropriações familiares, comunitárias, coletivas). Essas "terras tradicionalmente ocupadas" vão para além do modelo da propriedade individual, como nas "terras de preto", "terras de santo", "terras de índio", nos "faxinais", nos "fundos de pasto" etc. - A racionalidade.

O exame da prática da cultura camponesa, e de seus recursos concernentes e características de desenvolvimento rural colabora para rever o sentido desumano do capital urbano-industrial salientando padrões consideráveis em diversos contornos espaciais do país. Posteriormente, uma matriz original de apoderamento e uso da terra se reconfigura, e uma nova realidade/identidade se autentica em tempos de marginalidade e exclusão. O Sistema Maxwell, vinculado à VRAC - Vice-Reitoria para Assuntos Acadêmicos da PUC-RIO (2020, p. 14) atesta que "conceito de identidade tem sua origem na filosofia. Utiliza-se este conceito para descrever algo que é diferente dos demais, porém idêntico a si mesmo". Assim o site define que "a identidade é formada dialeticamente entre indivíduo e sociedade" sendo a mesma "mutável em boa medida inconscientemente, num processo que inclui a identificação própria e a identificação reconhecida por outros” (SISTEMA MAXWELL, 2020, p. 14).

Para Nascimento (2009, p. 13):

\begin{abstract}
A perspectiva dos camponeses/as numa visão pessimista seria o desaparecimento, a migração para os grandes centros urbanos ou o reiniciar a luta pela terra; alguns se incorporando ao sistema, assumindo as novas tecnologias, reformando-se com tecnologias alternativas, transformando-se por meio da cooperação agrícola ou reorganizando-se com novas experiências. A perspectiva dos pequenos, ao qual chamo de excluídos/as, pode estar vinculada a agricultura camponesa familiar a partir da criação de alternativas como é o caso das experiências das cooperativas. As cooperativas são uma contribuição especial para o projeto alternativo, pois pode gerar empregos, barateando os alimentos e liberando venda para outros setores da economia, além de melhorar as condições de vida do povo.
\end{abstract}

No entendimento teórico dessa "identidade", em especial de uma identidade rural (latifundiários) ou camponesa (agricultor familiar) há limitações estruturais. Contudo, falta contribuir pela incessante evidenciação das diferentes realidades rurais presentes no país, realçando seus elementos princípios e possibilidades que vençam de uma vez por todas a fantasia de que "a solução para a felicidade" se alcança unicamente nas cidades grandes. Ainda de acordo com Nascimento (2009, p. 14): 
Para que isso se efetive, é necessária uma inversão política por parte das políticas públicas referentes aos projetos agrários. Neste sentido, é preciso ver: os camponeses/as como sujeitos históricos deste projeto de desenvolvimento que buscam na agricultura familiar a base de suas lutas; políticas voltadas para a segurança alimentar; efetivação da reforma agrária e eliminação dos latifúndios; os estímulos a pequenos e médios agricultores/as para que recuperem a terra; a valorização da agricultura familiar quebrando, conseqüentemente, o monopólio privado das agroindústrias; políticas agrícolas voltadas à agricultura familiar; e o desenvolvimento de um amplo programa de educação para as escolas do campo.

Para isso faz-se necessário, fundamentações e bases teóricas que legitimam cultura camponesa na contemporaneidade e teçam construções sólidas em prol do desenvolvimento rural sustentável do país, destacando-se as propostas atuais e/ou pretéritas de viabilização de cursos interdisciplinares, técnico-profissionalizantes e/ou graduação-especialização nas áreas de Agroecologia, Educação do Campo e Turismo Rural enquanto frentes estratégicas de resistência, ressignificação e o consecutivo desenvolvimento sustentável dos estudantes camponeses. Para compreender isso definiu-se a análise da oferta de cursos, na modalidade EAD/Presencial, elencando-se 23 instituições privadas, em 09 unidades da federação, distribuídas nas cinco regiões do país, sendo uma de abrangência nacional, 01 sediada no Distrito Federal, 01 no Mato Grosso do Sul, 01 no Espirito Santo, 01 em Minas Gerais, duas no Rio de Janeiro, 09 em São Paulo, 04 no Paraná, 01 no Rio Grande do Sul e 03 em Santa Catarina. Uma universidade sediada em Taubaté, no estado de São Paulo é a única de caráter municipal no contexto geral de análise.

No âmbito dessas vinte e quatro instituições de ensino superior, espalhadas pelo país, listaram-se a existência regular de 01 curso de Agroecologia, sendo apenas ofertado na modalidade à distância, 17 cursos de Agronegócio, sendo 15 na modalidade à distância e 02 na modalidade presencial e 14 cursos de Agronomia/Engenharia Agronômica, sendo 02 na modalidade à distância e 12 na modalidade presencial.

\section{Cultura camponesa e desenvolvimento rural sustentável: fundamentação e bases teóricas}

Num cenário de expansão do agronegócio, mas do que nunca é primordial que camponeses se autoafirmem e consigam fortalecer seu lugar na articulação societária contemporânea. Existem incontáveis ligações interdisciplinares entre ecologia, história e geografia na concepção das numerosas perspectivas teóricas que integram o campesinato. A percepção do lugar, seja ele urbano ou rural, é modernamente uma das diversas formas pedagógicas de conceber e estudar as manifestações dos enfrentamentos entre o homem e a natureza. Observações atuais da percepção humana têm esclarecido visões teóricas e ângulos epistemológicos no concernente ao universo de signos, significados, significantes presentes na ligação de identidade e pertencimento ao lugar. O Sistema Maxwell (2020, p. 15) 
Instituições dominantes também podem formar identidades quando os atores sociais as interiorizam, construindo o seu significado com base nessa interiorização. Castells ${ }^{6}$ apresenta, além da individual, a identidade coletiva e diz que a construção social da identidade ocorre por relações de poder entre formas e origens. Uma identidade é considerada por ele como "legitimadora" quando é introduzida por uma instituição dominante visando sua expansão e também a racionalização da sua dominação. A identidade "de resistência" é criada por atores desfavorecidos ou desvalorizados, segundo a lógica da dominação, que constroem trincheiras de resistência e sobrevivência para si. A identidade "de projeto" caracteriza-se por ser construída por atores visando uma redefinição das suas posições na sociedade, provocando transformações sociais, como, por exemplo, o feminismo.

Destacam-se, muitas áreas cientificas que hoje se debruçam sobre a realidade agrária/agrícola do país, dentre as quais, a Agroecologia, o Agronegócio, a Agronomia, a Antropologia, a Arqueologia, as Ciências Biológicas, as Ciências Sociais, a Ecologia, a Engenharia Agrícola, a Engenharia Florestal, a Filosofia, a Geografia, a Gestão Ambiental, a História, a Literatura, a Psicologia, o Serviço Social, e o Turismo. Mas a grande maioria se dedica apenas às abordagens tecnicistas, eximindo-se de análises mais subjetivas e/ou existencialistas. Entre os muitos conceitos desta nova forma de analisar destacam-se os conceitos de Cultura Camponesa, de Espaço Camponês, de Habitat Camponês, de Identidade Camponesa, de Pertencimento Camponês, de Tempo Camponês, de Territorialidade Camponesa, quatro deles explicitados em notas de rodapé anteriores. Sobre essa temática enriquecedora, escritos de Tardin (2012, p. 181-182) fundamentam que:

\begin{abstract}
No Brasil, povos originários, povos africanos negros e povos europeus foram condicionados historicamente a se encontrar neste vasto território, sob o domínio das nobrezas de alguns países europeus, notadamente Portugal e Espanha, e vão conformando o miscigenado campesinato brasileiro (ver implicações desses condicionamentos em Campesinato). Essa miscigenação tem continuidade histórica no país não só em decorrência da vinda de outros povos para o Brasil, mas também pelo intenso processo migratório existente no campo até os dias atuais. Essa constituição pluriétnica cada vez mais miscigenada vai gestar tipos humanos diferenciados e regionalizados territorialmente, os quais, em suas interações com os ambientes específicos de cada lugar, vão configurar as paisagens com suas peculiaridades culturais: os povos originários, majoritariamente na Amazônia e dispersos nas demais regiões; o sertanejo, no Agreste nordestino; os quilombolas, dispersos em várias regiões; o ribeirinho, às margens de rios; o caipira, em partes do Sudeste; o caboclo, em partes do Nordeste e da Amazônia; o gaúcho, nos pampas sulinos; o colono imigrante europeu, no Sul e em partes do Sudeste, entre outros. Na condição predominante de trabalhadores sem-terra, estão o peão de boiadeiro, o pantaneiro, o agregado, o meeiro, o parceiro e, nas vilas e cidades predominantemente, o boia-fria.
\end{abstract}

Para instigar este saber intricado, numa esfera de sentidos e significados que abarcam o mundo camponês destacam-se princípios mais adjuntos das áreas da ecologia, geografia e história. Isso se deve ao caso dessas três extensões do conhecimento debaterem com certa periodicidade, saberes teóricos e argumentos temáticos acerca de a existência agrária/agrícola e o mundo rural/camponês. Logo, destacam-se as colaborações científicas da Filosofia e da

${ }^{6}$ CASTELLS, Manuel. O poder da identidade. São Paulo: Paz e Terra, 2001. 
Psicologia Social para expandir a consciência dos sistemas fisiológicos e existenciais que transpassam o panorama didático-pedagógica da percepção. A Percepção é simplesmente uma das tantas capacidades de investigação do espaço rural e das convivências se desenvolvem sobre ele. Nesta conjuntura, na percepção e compreensão da integralidade do lugar perseveram infinitos vínculos filosóficos e psicológicos, determinantes a compreensão das perspectivas pessoais e coletivas de espacialidade/temporalidade, saberes/fazeres e jeitos de ser/estar no mundo. Sobre este tema e concepções, de acordo com Nascimento (2009):

\begin{abstract}
Um grande desafio a ser vencido na realidade social do meio rural são os muitos conceitos que qualificam ou desqualificam os habitantes do campo. Tais conceitos podem ser valorativos ou depreciativos, além de muitos serem pejorativos. Por exemplo: é pejorativo conceber aos camponeses/as os estereótipos de atrasados, preguiçosos, ingênuos e incapazes, porque tal postura só vem demonstrar uma espécie de racismo rural disfarçado e camuflado.
\end{abstract}

Neste quadro, as muitas extensões do conhecimento científico que ponderam e compõem conhecimentos teóricos sobre a vida agrária/agrícola e o mundo rural/camponês serão rapidamente expostas na continuação, sendo que se dará maior destaque às áreas da agroecologia, educação e do turismo, ordens científicas arroladas como segmentos determinantes nas etapas históricas do desenvolvimento rural sustentável do país. Tanto a agroecologia, como a educação e o turismo são interessantes meios didático-pedagógicos a serem utilizados interdisciplinarmente, na educação básica na área de Ciências Sociais e Humanidades em disciplinas como Filosofia, Geografia, História, Língua Portuguesa e Sociologia provendo então elos para revisar a ligação campo/cidade campesinato e ressignificar o imaginário social e a percepção cultural sobre a paisagem camponesa (FIGURA 02). Compreendendo a ecologia e a gestão ambiental como junções de persistência à difusão desregrada do agronegócio, um quadro importante de termos com signos, significados e significantes se efetiva através dos termos: agricultura, caipira, campesinato, cultura, essência, estereótipo, identidade, música, paisagens, patrimônio e ruralidade.

Figura 02 - Paisagem Camponesa retratada em tela de Túlio Dias

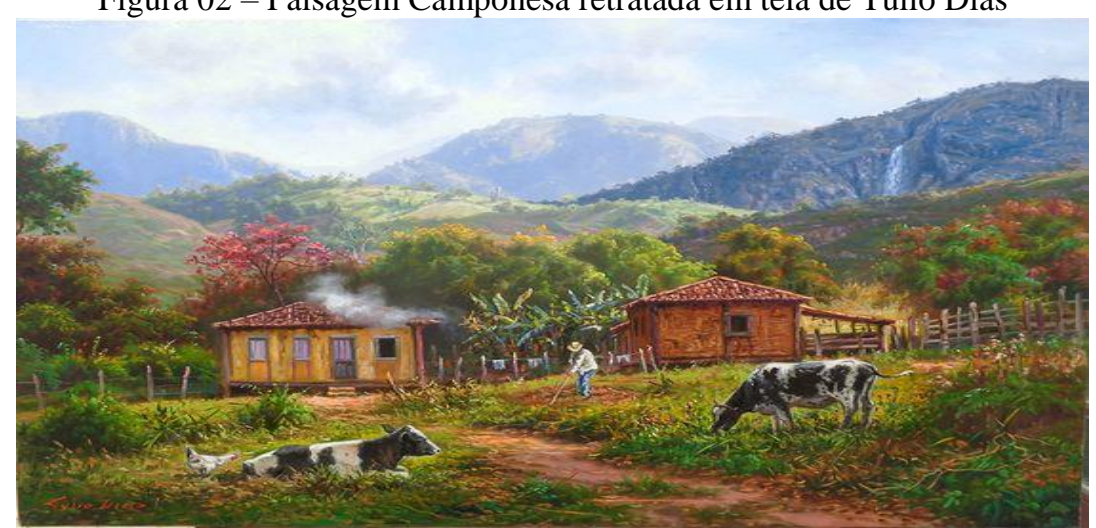

Fonte: https://www.pinterest.ch/pin/589971619914371564/. Acessado em: 14/11/2020. 
Neste cenário, este trabalho caracteriza-se como uma discussão inicial sobre as várias propostas de viabilização de cursos de Agroecologia, Educação do Campo e Turismo encontram-se em processo de consolidação por todo país, com rupturas, permanências e alternâncias. Essas áreas de formação se destacam enquanto estratégias de desenvolvimento rural sustentável. São cursos que partem da tradicional especificidade associada ao agronegócio e à agronomia e buscam novas frentes de discussão e de atuação. Lamentavelmente muitos cursos de Agroecologia, Ecologia, Educação do Campo e Turismo tem se extinguido no país. A Universidade do Contestado - UNC, por exemplo, sediada em Santa Catarina ofertou durante um tempo, a graduação em Agroecologia e Desenvolvimento Rural Sustentável, em nível de bacharelado, porém o curso se extinguiu.

Também em terras catarinenses, a Universidade do Sul de Santa Catarina - UNISUL, ofertava a graduação em Turismo com ênfase em Gestão de Negócios Agrícolas, mas a estrutura curricular foi modificada. Para o discente que optasse por esta titulação ele deveria matricular-se em três disciplinas específicas, num conjunto de seis opções: 1-Cooperativismo Rural, 2-Desenvolvimento Rural Integrado, 3-Patrimônio Cultural e Natural, 4-Patrimônio Cultural e Turismo, 5-Patrimônio Natural e Turismo e 6-Planejamento e Gestão de Negócios Agroturísticos. Na UNISUL, o curso de bacharelado em Turismo, na modalidade EAD, permanece ativo, porém sem mais ofertar a respectiva ênfase rural. Nos tempos atuais destaca-se a Universidade Municipal de Taubaté - UNITAU, em São Paulo com diferencial em nível nacional, ao ofertar o Tecnólogo em Agroecologia de 2.700 horas, na modalidade EAD (Quadro III). A instituição também a oferta de Agronegócio, porém sem ênfase mercadológica como as demais instituições. As disciplinas da UNITAU, no curso de Agronegócio se respalda nos processos produtivos sustentáveis. A página do curso no Site da UNITAU (2020) confabula que:

O Curso Superior de Tecnologia em Agroecologia da EAD Unitau, a partir de forte base conceitual, objetiva formar profissionais capacitados para atuarem efetivamente no mercado de trabalho, permitindo que possam, de forma especializada, produzir, planejar, executar, monitorar, analisar e certificar sistemas de produção agroecológica. Espera-se que o aluno, ao final do curso, utilizando-se de modernas metodologias e tecnologias de produção, consiga identificar as oportunidades, a diversificação e o aumento da produção, bem como a qualidade dos produtos. $\mathrm{O}$ profissional formado em Tecnologia em Agroecologia também poderá atuar nos processos de transição agroecológica com base na agricultura familiar. As atividades e provas presenciais deste curso são realizadas trimestralmente, um final de semana por mês (aos sábados, das $8 \mathrm{~h}$ às $17 \mathrm{~h}$, e domingos, das $8 \mathrm{~h}$ às $12 \mathrm{~h}$ ), no Polo de Taubaté/SP. 
ANDRADE, V. L; DIB, A. P. S.

Educação do Campo e Turismo Rural como Resistências à Expansão Desenfreada do Agronegócio: Cursos Propostos e Viabilizados de Desenvolvimento Agroecológico Enquanto Estratégias de Gestão Socioambiental

Quadro III - Universidade de Taubaté - UNITAU, São Paulo - Estrutura Curricular do Curso Tecnólogo em Agroecologia de 2.700 horas, ofertado na modalidade EAD

\begin{tabular}{|c|c|c|}
\hline Código & Disciplinas - UNITAU & C.H. \\
\hline 00131247 & Agroecologia & 100 horas \\
\hline 00131265 & Atividades Complementares do Curso - ACC & 100 horas \\
\hline 00131269 & Agroecologia na Agricultura Familiar & 80 horas \\
\hline 00131270 & Apicultura orgânica & 100 horas \\
\hline 00131271 & Associativismo, Cooperativismo, Cadeias e Arranjo Produtivo Local & 100 horas \\
\hline 00131272 & Avicultura e Suinocultura Orgânicas & 100 horas \\
\hline 00131273 & Bovinocultura Orgânica & 100 horas \\
\hline 00131274 & Caprinocultura e Ovinocultura Orgânicas & 100 horas \\
\hline 00131275 & Construções Rurais e Implementos Agrícolas & 100 horas \\
\hline 00131276 & Empreendedorismo e Plano de Negócio & 100 horas \\
\hline 00131277 & Ética e Responsabilidade Social & 100 horas \\
\hline 00131278 & Etnobotânica e Quintais Produtivos & 100 horas \\
\hline 00131279 & Fruticultura Agroecológica & 100 horas \\
\hline 00131280 & Manejo Agroecológico de Pragas e Doenças & 100 horas \\
\hline 00131281 & Manejo Agroecológico e Conservação do Solo & 100 horas \\
\hline 00131282 & Olericultura Agroecológica & 100 horas \\
\hline 00131283 & Plano de Manejo de Polinizadores e Polinização & 100 horas \\
\hline 00131284 & Plantas Medicinais, Aromáticas e Condimentares & 100 horas \\
\hline 00131285 & Produção Agroecológica de Graníferas & 100 horas \\
\hline 00131286 & Recursos Hídricos: Manejo e Gerenciamento & 100 horas \\
\hline 00131287 & Sistemas Agroflorestais (SAFs) & 100 horas \\
\hline 65635001 & Educação Ambiental para a Sustentabilidade & 80 horas \\
\hline 65644001 & Tecnologia do Processamento Vegetal e Animal & 100 horas \\
\hline 65650001 & Gestão da Qualidade e Certificação & 80 horas \\
\hline 65667001 & Piscicultura & 80 horas \\
\hline 65681001 & Apiculturismo & 80 horas \\
\hline 65689001 & Biotecnologia & 80 horas \\
\hline 67543001 & Custo e Formação de Preço & 80 horas \\
\hline 67549001 & Estágio Supervisionado & 200 horas \\
\hline 67602001 & Língua Brasileira de Sinais - LIBRAS & 80 horas \\
\hline & CARGA HORÁRIA TOTAL DO CURSO & 2700 horas \\
\hline
\end{tabular}

Fonte: adaptado de https://unitauead.com.br/cursos/graduacao/superior-de-tecnologia/agroecologia/. Acessado em: 10/10/2020.

Analise o processo formativo no curso da UNITAU, o mesmo pode ser compreendido a partir de seis eixos temáticos: Eixo temático I - Elementos de Ecologia e Gestão Ambiental (Agroecologia, Biotecnologia, Manejo Agroecológico de Pragas e Doenças, Manejo Agroecológico e Conservação do Solo e Plano de Manejo de Polinizadores e Polinização); Eixo temático II - Fundamentos de Agropecuária (Agroecologia na Agricultura Familiar, Apicultura Orgânica, Etnobotânica e Quintais Produtivos, Recursos Hídricos: Manejo e Gerenciamento e Sistemas Agroflorestais - SAFs); Eixo temático III - Produção Vegetal Orgânica (Atividades Complementares do Curso - ACC, Fruticultura Agroecológica, Olericultura Agroecológica, Plantas Medicinais, Aromáticas, Condimentares e Produção Agroecológica de Graníferas); Eixo temático IV - Produção Animal Orgânica (Apiculturismo, Avicultura/Suinocultura Orgânicas, Bovinocultura Orgânica, Caprinocultura/ Ovinocultura Orgânicas e Piscicultura); Eixo temático V - Desenvolvimento Rural Integrado 
(Associativismo, Cooperativismo, Cadeias, Arranjo Produtivo Local, Construções Rurais e Implementos Agrícolas, Educação Ambiental para a Sustentabilidade, Estágio Supervisionado e Língua Brasileira de Sinais - LIBRAS) e Eixo temático VI - Mercado e Comercialização (Custo/Formação de Preço, Empreendedorismo/ Plano de Negócio, Ética e Responsabilidade Social, Gestão da Qualidade/Certificação e Tecnologia do Processamento Vegetal e Animal). A estrutura curricular do curso é ampla e rica no que tange a relação harmônica do camponês para com os recursos naturais (Figura 03), sendo o que falta seria a oferta das disciplinas de Educação do Campo e Turismo Rural como optativas. Similar a este relevante curso, consolida-se em Minas Gerais, na Grande BH um curso de Agroecologia, em Ibirité, porém, apenas na modalidade técnico-profissionalizante, conforme descrito no Site da FHA Fundação Helena Antipoff (2020, p.08):

O Curso de Técnico em Agroecologia Subsequente ao Ensino Médio em regime de alternância, pertence ao Eixo Recursos Naturais e será ofertado na Escola Técnica Sandoval Soares de Azevedo da Fundação Helena Antipoff (FHA) na modalidade presencial com carga horária total de 1.625 horas, dividida em 3 (três) módulos semestrais. O curso desenvolver-se-á conforme indicado no Catálogo Nacional de Cursos Técnicos, no Parecer CNE/CEB n 1/2006 e na Resolução CNE/CEB nº 6, de 20 de setembro de 2012 que Define Diretrizes Curriculares Nacionais para a Educação Profissional Técnica de Nível Médio. O Curso contará com a parceria da Universidade Federal de Viçosa - Campus Florestal, e futuramente pretende-se contar com mais parcerias, entre Instituições/Organizações da Sociedade Civil e do Estado.

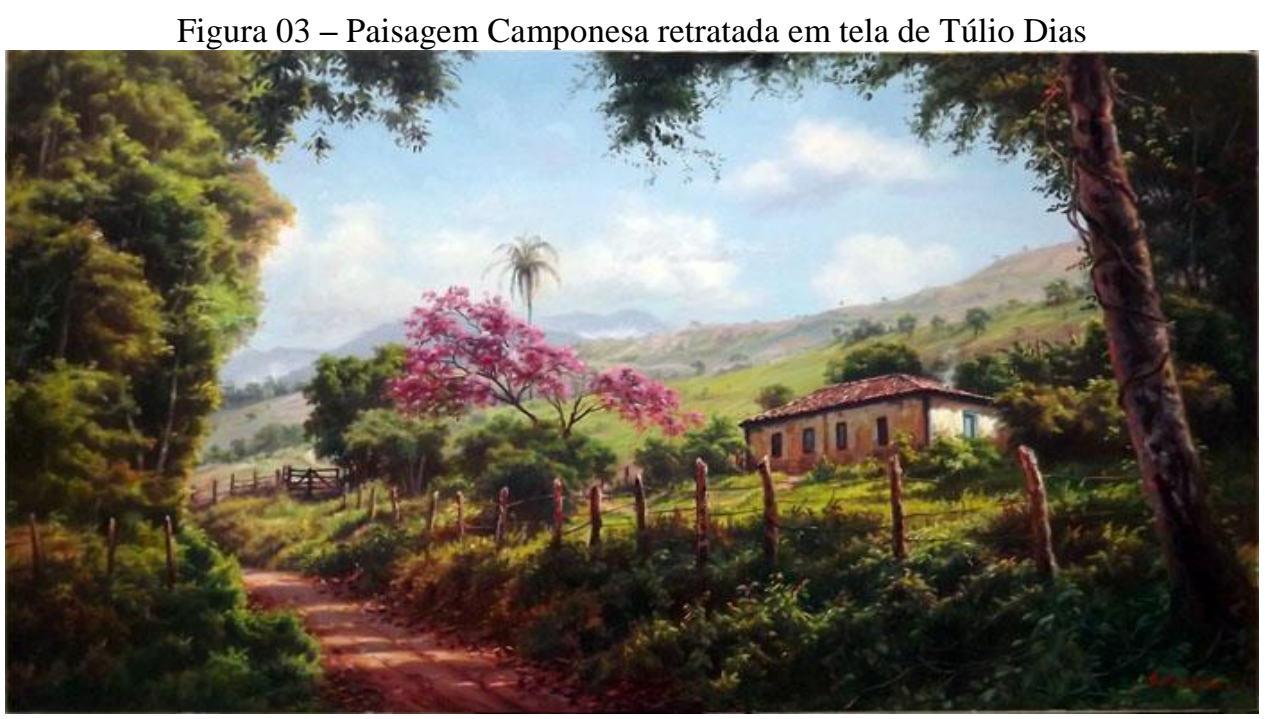

Fonte: https://tuliodiasartes.blogspot.com/p/obras-2013.html. Acessado em: 11/10/2020.

Como anteriormente foi analisando apenas a oferta regular de cursos de Agroecologia, Agronegócio e Agronomia/Engenharia Agronômica, nas modalidades à distância e presencial em vinte e quatro instituições de ensino superior analisadas, por sua vez espalhadas pelo país, é preciso conhecer a existência e como esta oferta encontra-se consolidada e ofertada na rede de unidades públicas de ensino superior. Verificou-se a partir da base de dados do MEC: 
sendo 27 cursos de Agroecologia (Bacharelado ou Tecnologia), 110 cursos de Agronomia (Bacharelado), 510 cursos de Agronegócio (Tecnologia), 56 cursos de Educação do Campo (Licenciatura) e aproximadamente 140 cursos de Turismo (Bacharelado ou Tecnologia), sem apresentar, portanto, diferenciações quantitativas entre a modalidade à distância e a modalidade presencial, sendo esta última mais comum. Ao verificar lacunas no processo de formação de agentes profissionais para atuação cultural junto às comunidades camponesas, nota-se também a desconstrução de políticas públicas significativas para o campesinato, e que precisam ser resgatadas e/ou revigoradas. Um detalhamento maior foi dado ao estado de Minas Gerais.

Em terras mineiras, especificamente no entorno da capital, a sugestão é a oferta de um Curso de bacharelado em Agroecologia e Desenvolvimento Rural Sustentável, na Unidade Ibirité, da Universidade Estadual de Minas Gerais, com seis módulos, duração de três anos, 56 disciplinas de 60 horas e carga horária total de 3360 horas. As disciplinas obrigatórias somam-se o Estágio Curricular Obrigatório I, no módulo V e Estágio Curricular Obrigatório II, no módulo VI. O Módulo I do Bacharelado em Desenvolvimento Rural Sustentável (Associativismo e Extensão Rural, Ciência dos Solos I, Desenho Técnico, Educação do Campo I, Elementos de Zootecnia I, Fundamentos da Agricultura I, Gestão Ambiental e Irrigação e Drenagem I). O Módulo II do Bacharelado em Agroecologia (Administração Rural I, Ciência dos Solos II, Construções e Instalações Rurais I, Elementos da Agroindústria I, Fundamentos da Agricultura II, Fundamentos de Topografia I, Irrigação e Drenagem II, Mecanização Agrícola I e Turismo Rural I). O Módulo III do curso de Bacharelado em Desenvolvimento Rural Sustentável (Administração Rural II, Construções e Instalações Rurais II, Elementos da Agroindústria II, Elementos de Zootecnia II, Fundamentos da Agricultura III, Fundamentos de Topografia II, Introdução ao Empreendedorismo e Saúde e Segurança no Trabalho). Segundo apresentado no Site da FHA - Fundação Helena Antipoff (2020, p.12):

A oferta do Curso Técnico em Agroecologia Subsequente ao Ensino Médio em regime de alternância integra os programas e ações do governo de Minas Gerais de democratização do acesso à educação profissional e tecnológica para públicos de acampamentos e assentamentos de reforma agrária, agricultores familiares, quilombolas, pequenos produtores e trabalhadores rurais e, de atendimento à uma demanda de expansão da agricultura camponesa e agroecológica em defesa da vida e em alternativa à agricultura convencional, numa perspectiva da sustentabilidade social, política, ambiental, econômica e cultural, da emancipação dos sujeitos e de mudança de paradigma no consumo para produção agroecológica. O Plano de Curso surge da compreensão de difundir novos modelos de produção que estimulem maior integração entre os sujeitos e a natureza, e a natureza e os sujeitos. Dessa forma, o perfil profissional proposto para o curso se difere dos demais profissionais do ramo por ter uma visão holística dos agroecossistemas, ter aptidão para implantar arranjos produtivos de base ecológicos através de tecnologias de fertilização biológica e 
O Módulo IV do Bacharelado em Agroecologia (Agroecologia e Sistemas Agrários, Biologia Vegetal, Campesinato e Agronegócio, Ecossistemas e Agroecossistemas, Elementos de Zootecnia III, Informática Aplicada, Matemática Aplicada, Sementes e Propagação de Plantas, Sistemas Agroecológicos de Produção Animal I, Sistemas Agroecológicos de Produção Vegetal I e Topografia, Cartografia e Irrigação). o Módulo V do Bacharelado em Desenvolvimento Rural Sustentável (Ciência dos Solos III, Cooperativismo e Cooperação Agrícola, Cultivos Agroecológicos, Elaboração e Análises de Projetos Agroecológicos, Português Instrumental, Sistemas Agroecológicos de Produção Animal II, Sistemas Agroecológicos de Produção Vegetal II e Tecnologia e Processamento de Alimentos). O Módulo VI do Bacharelado em Agroecologia (Educação do Campo II, Gestão de Unidades Produtivas Agroecológicas, Manejo e Conservação Agroecológica do Solo e da Água, Mecanização Agrícola II, Metodologia de Iniciação Científica, Sistemas Agroecológicos de Produção Animal III, Sistemas Agroecológicos de Produção Vegetal III, Sistemas Agroflorestais e Turismo Rural II).

A oferta de tal curso traz novas significações e contexto para comunidades e paisagens rurais dimensionando-as enquanto componentes da diversidade cultural e socioeconômica do Brasil. É, sobretudo, romper com dicotomias historicamente alicerçadas no cerne da sociedade brasileira. Esse modelo socioeconômico, no qual a incessante industrialização avivou a urbanização, acirrando a fixação do agronegócio, o esbanjamento da natureza, colocando-a ao uso de poucos pessoas com suas inclinações de lucro e poder, omitindo igualmente o benefício comum da sustentabilidade, é imprescindível a humanidade, e suas renovações (FIGURA 04).

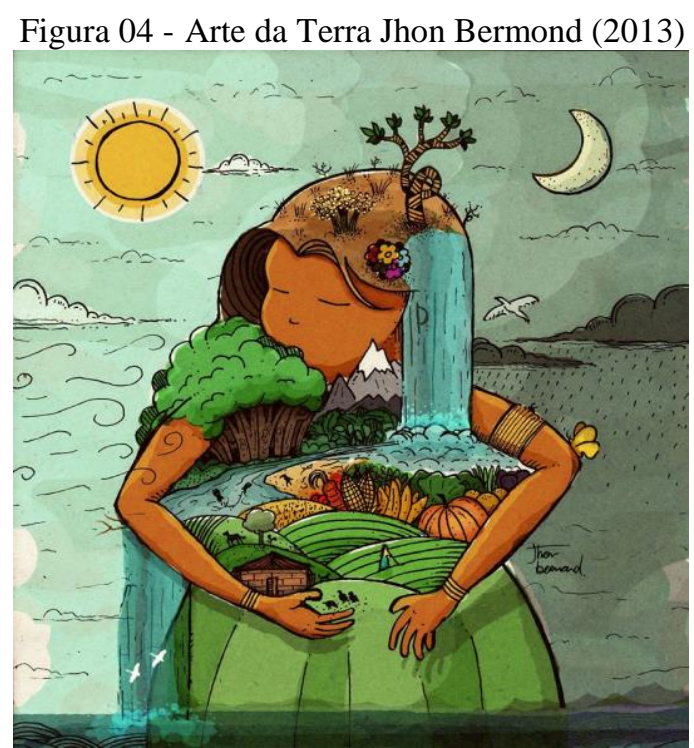

Fonte: https://www.facebook.com/bermond.jhon/photos/a.3795804021687. Acessado em: 09/10/2020. 
Infelizmente, o consumo da contemporaneidade desempenha uma impressionante coerção sobre a natureza e sobre o universo camponês/rural. No meio de numerosas máculas identificadas, distingue-se uma ruptura cada vez mais gradual com a natureza, ponderada em manifestações desiguais, dentre as quais, a paulatina depreciação das existências culturais campesinas. A atual veracidade camponesa no esfera internacional vem salientando infinitas deformações sociais, como a forte urbanização, subsequente de incontáveis questões impostas ao pequeno produtor campestre, que excluído do campo, se destina para os grandes centros urbanos concretizando novas concepções de vida. Neste contexto, a cultura camponesa terminou sendo desprezada ou ponderada como sinônimo de demora e regresso e perante disso, avolumou excessivamente a subserviência e subordinação do campo em comparação às urbes. Num prisma onde homem e natureza se converteram em elos bifurcados e divergentes, o campo e cidade se metamorfosearam cada vez mais alheios e ampliam o estranhamento.

\section{Considerações finais}

Consagradamente há uma divergência cultural entre campo e cidade que não tem sido propriamente valorizada. Segundo incontáveis estudos, perseveram vários aspectos de exclusão do campo, que acarretam a ruptura do pequeno agricultor com sua realidade local, estimulando o esvaziamento do campo e consecutivo inchaço das urbes. Dentre alguns desses elementos de expulsão, podem-se frisar a deterioração e subsequente esgotamento dos elementos naturais; a ocasião de catástrofes e/ou hostilidades ambientais; a definição das políticas públicas voltadas à desenvolvimento da insustentabilidade rural; a inutilidade de alguns regras usuais de produção; os limites dos esboços de assistência técnica rural; a escassez de projetos pedagógicos voltados à veracidade e a peculiaridade do campo; bem como a concentração de terras, a mecanização agrícola e a estabelecimento de monoculturas. Tristemente este quadro preocupante deixa seres vivos, sociedade e recursos naturais à mercê da ambição do sistema socioeconômico, gerando forças dispares que deterioram a qualidade de vida e lesam a dignidade humana. Um fato que acontece e determina condenação a infinitas comunidades rurais, que se converteram unicamente em espaços produtores de várias matérias primas e produtos, direcionados para dentro do progressivo consumo da crescente coletividade urbano-industrial.

Para se cumprir aos preceitos capitalistas, o patrimônio ambiental agregado nestas comunidades acabou sendo incessantemente aproveitado de matriz predatória, transgredindo a aptidão e suporte do mesmo e resultando em inúmeros problemas socioambientais. Surgindo esta prática perfizeram conflitos entre os espaços camponeses e urbanos e entre grandes produtores rurais, desejosos por lucro e pequenos agricultores ligados a terra, na qual obtêm a "suada" sobrevivência. Perante desse consumo exacerbado, que motiva a dilapidação 
ambiental, desconformidades sociais, indeterminações e dificuldades de perspectivas, acaba persistindo ao pequeno produtor unicamente uma alternativa, ou suportar resguardando seu elo harmônico com a terra de seus antepassados ou expirar obedecendo a voracidade do sistema opressor. Se a opção definida for à segunda, restará um único destino, a contínua extração dos recursos naturais até a esgotamento deles, estimulando o interrupção total com a realidade rural, levando-o a querer possibilidades alternativas nas cidades.

Esta eliminação do homem do campo, o faz rescindir com sua cultura de relacionamento sustentável com a terra, levando-o a conjecturar os atributos das grandes cidades, estimulando quimeras que serão futuramente transformadas em desencanto e exclusão. Ao se dirigir à grande urbe com pretensão de novos ângulos e progressos e sem qualificação, sem emprego, sem perspectivas, ele e sua família estarão fadados à integração nas dificuldades periféricas, na maioria dos fatos sem direito a chances dignas de vida, avultando os índices de alienação, degradação dominação, e exploração, já tão gerais na sociedade contemporânea.

O agronegócio é um grande potencial da economia brasileira, porém para que o mesmo se adeque à competitividade e as exigências do mercado consumidor modernos, ele precisará fazer concessões significativas com vistas à minimizar conflitos, até que se possa anular os impactos sociais e ambienteis de um modelo produtivo ainda demasiadamente concentrado na monocultura e no latifúndio. Assim uma das formas pelas quais ele poderá se adaptar às demandas sociais por alimentação saudável, é de que não se impacte as comunidades e ecossistemas nos quais esteja localizado. A segurança alimentar, é um pressuposto inegável que rege à vida coletiva. Do pobre marginalizado e excluído ao rico fazendeiro, a alimentação, que é um direito fundamental tem que ser pensada de outra forma. Assim para o bem de todos os produtores a consumidores, o agronegócio se manterá apenas se incorporar o conceito de produção agroecológica para produção em escala.

\section{Referências}

ALTIERI, Miguel. Agroecologia: a dinâmica produtiva da agricultura sustentável. $4^{\mathrm{a}}$.ed. - Porto Alegre: Editora da UFRGS, 2004. 20 Disponível <https://s3.wreducacional.com.br/13/2088/4708.pdf> Acesso em 20. Mai. 2020

ANDRADE, Vagner Luciano de. Opinião: Era pós-contemporânea ou tecnológica? In: Boletim UFMG. $\quad \mathrm{N}^{\mathrm{o}} 1885$ - Ano 41, Publicado em 17.11.2014. Disponível em < https://www.ufmg.br/boletim/bol1885/2.shtml> Acesso em 20. Mai. 2020

BALLA, João Vitor Quintas; MASSUKADO, Luciana Miyoko; PIMENTEL, Vania Costa. Panorama dos cursos de agroecologia no Brasil. In: Revista Brasileira de Agroecologia. 9(2): 3-14 (2014). . Disponível em <https://orgprints.org/27319/1/Balla_Panorama\%20dosos.pdf> Acesso em 20. Mai. 2020 
BRASIL. DECRETO No 7.352, DE 4 DE NOVEMBRO DE 2010: Dispõe sobre a política de educação do campo e o Programa Nacional de Educação na Reforma Agrária - PRONERA. Disponível em <http://portal.mec.gov.br/docman/marco-2012-pdf/10199-8-decreto-7352-de4-denovembro-de-2010/file> Acesso em 20. Mai. 2020

BRASIL. Oferta de cursos de Licenciatura em Educação do Campo - PROCAMPO. Disponível em $\quad<$ http://portal.mec.gov.br/pet/194-secretarias-112877938/secad-educacao-continuada223369541/18784-oferta-de-cursos-de-licenciatura-e> Acesso em 20. Mai. 2020

CALDART, Roseli Salete (Org.). Dicionário da Educação do Campo. Rio de Janeiro, São Paulo: Escola Politécnica de Saúde Joaquim Venâncio, Expressão Popular, 2012. 788 p. . Disponível em $<$ http://www.epsjv.fiocruz.br/sites/default/fpdf> Acesso em 20. Mai. 2020

CARVALHO, Diana Mendonça de; COSTA, José Eloízio da. CADEIA PRODUTIVA E COMERCIALIZAÇÃO AGRÍ́COLA NO BRASIL. In: Revista GeoNordeste. $\mathrm{N}^{\circ} 2$, Ano XXIV Edição Especial 2013, p. 33. Disponível em https://seer.ufs.br/index.php/geonordeste/article/view/1509 > Acesso em 20. Mai. 2020

CHAGAS, Juarez e Silva. A Morte e suas Representações. Jundiaí: Paco Editorial, 2015. 280 p. . Disponível em https://books.google.com.br/books/about/A_Morte_E_Suas_Representa\%C3\%A7\%C3\%B5es.html?id =q2pruQEACAAJ \&redir_esc $=y>$ Acesso em 20. Mai. 2020

CHAPLIN, Charles. O Caminho da Vida. In: Site Pensador. Disponível em <https://www.pensador.com/frase/MjU2MjM/> Acesso em 20. Mai. 2020

CRUZ, Valter do Carmo. Povos e comunidades tradicionais. In: CALDART, Roseli et al. Dicionário da educação do campo. Rio de Janeiro: Escola Politécnica de Saúde Joaquim Venâncio. São Paulo: Expressão Popular, 2012.

FREITAS, C. B.; PINHO, L. A.; ANTUNES-ROCHA, M. I. Educação do Campo: da luta à conquista de direitos. Belo Horizonte: FaE/CAED/UFMG, 2013. 44p.

FUNDAÇÃO HELENA ANTIPOFF. Plano de Curso Técnico em Agropecuária. Disponível em <http://www.fha.mg.gov.br/sites/default/files> Acesso em 20. Maio. 2020

FUNDAÇÃO HELENA ANTIPOFF. Escola Técnica Sandoval Soares de Azevedo. Disponível em <http://fha.mg.gov.br/pagina/fha/escola-tecnica> Acesso em 20. Mai. 2020

FUNDAÇÃO HELENA ANTIPOFF. Plano de Curso Técnico em Agroecologia Subsequente ao Ensino Médio em Regime de Alternância: Turma I. Ibirité - MG. Setembro/2018. Disponível em <http://www.fha.mg.gov.br/sites/default/files/documentos/pdf> Acesso em 20. Mai. 2020

GOMES, Thiago Oliveira. Formação superior em agroecologia e educação do campo: práticas sociais que transbordam áreas de conhecimento (Dissertação Pós- Graduação em Agroecologia). Universidade Federal de Viçosa Viçosa/MG. 2014.

GUIMARÃES, Alberto Passos. Quatro Séculos de Latifúndio. Rio de Janeiro, Editora. Paz e Terra, 1968.

LADWIG, Nilzo Ivo; COSTA, Rogério Santos da (org.). Vinte anos da queda do muro de Berlim : um debate interdisciplinar. Palhoça: Ed. Unisul, 2009. 183 p. Disponível em< https://riuni.unisul.br/bitstream/handle/12345/1940/Vinte\%20anos\%20da\%20queda\%20do\%20muro\% 20-\%20Ed\%20Unisul.pdf?sequence=1\&isAllowed=y> Acesso em 20. Maio. 2020

LEONIDIO, Adalmir. Sentido histórico do ódio e da crueldade no Brasil. In: Fragmentos Diversitas, Ano 1/N. 3, jul. 2017. 
MARQUESE, Rafael de Bivar. A dinâmica da escravidão no Brasil: Resistência, tráfico negreiro e alforrias, séculos XVII a XIX. In: Novos estudos CEBRAP no.74 São Paulo Mar. 2006. Disponível em <https://www.scielo.br/scielo.php?script=sci_arttext\&pid=S0101-33002006000100007> Acesso em 17. Mai. 2020

MEAD, Margareth. Nunca duvide. In: Site Pensador. Disponível em < https://www.pensador.com/frase/MTAyMDIxMA/ > Acesso em 20. Mai. 2020

MOURA, Antônio de Paiva. Médio Paraopeba e seu saber viver. Bonfim: Prefeitura Municipal, 2014.

NASCIMENTO, Claudemiro Godoy do. Educação do campo e a teoria critica em Gramsci. . Disponível em <http://universidadetuiuti.utp.br/Cadernos_de_Pesquisa/pdfs/cad_pesq8/6_educacao_campo_cp8.pdf> Acesso em 20. Mai. 2020

PEREZ, Frederico; ROZEMBERG, Brani (1999). Capítulo 15 - É VENENO OU É REMÉDIO? Os desafios da comunicação rural sobre agrotóxicos. Disponível em < https://portal.fiocruz.br/sites/portal.fiocruz.br/files/dpdf > Acesso em 20. Mai. 2020

PORTAL EAD. Carreiras: Curso de Ciências Agrárias em EAD. Disponível em <https://www.ead.com.br/carreiras/curso-de-ciencias-agrarias> Acesso em 20. Mai. 2020

RIBEIRO, Eduardo Magalhães. et al. Agricultura familiar e programas de desenvolvimento rural no Alto Jequitinhonha. In: Revista de Economia e Sociologia Rural. vol.45 no.4 Brasília Out./Dec. 2007. Disponível em < https://www.scielo.br/scielo.php?script=sci_arttext\&pid> Acesso em 20. Mai. 2020

RIBEIRO, Eduardo Magalhães; GALIZONI, Flávia Maria. Sistemas agrários, recursos naturais e migrações no Alto Jequitinhonha, Minas Gerais. In: TORRES, H.; COSTA, H. (Orgs.). População e meio ambiente: debates e desafios. São Paulo: Senac-SP, 2000.

SACCOMANI, Raquel; MARCHI, Luís Fernando Bartolomeu; SANCHES, Rosely Alvim. PRIMAVERA SILENCIOSA: uma resenha. In: Revista On Line Saúde em Foco UNIFIA. Edição n 010, Ano 2018 Página 739. Disponível em < http://portal.unisepe.com.br/unifia/saude-emfoco/ano-2018/ > Acesso em 20. Maio. 2020

SCORTEGAGNA, Liamara; DALMAGRO, Neide Maria. EDUCAÇÃO A DISTÂNCIA COMO FATOR INCLUSIVO NA AGRICULTURA FAMILIAR. Maio de 2009. Disponível em < http://www.abed.org.br/congresso2009/CD > Acesso em 20. Mai. 2020

TARDIN, José Maria. Cultura camponesa. In: CALDART, Roseli Salete (org.). Dicionário da Educação do Campo. Rio de Janeiro, São Paulo: Escola Politécnica de Saúde Joaquim Venâncio, Expressão Popular, 2012, p. 180-188. Disponível em < http://www.epsjv.fiocruz.br/sites/default/files/1191.pdf > Acesso em 20. Mai. 2020

UNIVERSIDADE DE TAUBATÉ - UNITAU. Curso Superior de Tecnologia em Agroecologia. Disponível em <https://unitauead.com.br/cursos/graduacao/superior-de-tecnologia/agroecologia/> Acesso em 20. Mai. 2020

UNIVERSIDADE DO CONTESTADO - UNC. BACHARELADO EM DESENVOLVIMENTO RURAL SUSTENTÁVEL E AGROECOLOGIA - CAMPUS CONCÓRDIA. Disponível em < https://www.universia.com.br/estudos/universidade-contestado/bacharelado-desenvolvimento-ruralsustentavel> Acesso em 20. Mai. 2020 
UNIVERSIDADE DO SUL DE SANTA CATARINA - UNISUL. Curso Superior de Tecnologia em Agronegócio. Disponível em <http://www.unisul.br/presencial/graduacao/gestao / > Acesso em 20. Mai. 2020

VICE-REITORIA PARA ASSUNTOS ACADÊMICOS da PUC-RIO. Biblioteca Virtual Maxwell. Asas como herança: Núcleo de Memória comemora 80 anos da PUC-Rio com marcos físicos e simbólicos e lança concurso de monografias. Disponível em <http://vrac.pucrio.br/cgi/cgilua.exe/sys/start.htm?> Acesso em 20. Maio. 2020.

Artigo recebido em: 11/11/2020. Artigo aceito em: 03/01/2021. 